\title{
The Production, Characterization, and the Stability of Carotenoids Loaded in Lipid-Core Nanocapsules
}

\author{
Médelin Marques da Silva ${ }^{1} \cdot$ Leonardo Nora $^{1} \cdot$ Rufino Fernando Flores Cantillano $^{2}$. \\ Karina Paese $^{3}$ - Silvia Stanisçuaski Guterres ${ }^{3}$ - Adriana Raffin Pohlmann ${ }^{4}$. \\ Tania Maria Haas Costa ${ }^{5}$ - Alessandro de Oliveira Rios ${ }^{6}$
}

Received: 28 July 2015 / Accepted: 22 February 2016

(C) Springer Science+Business Media New York 2016

\begin{abstract}
The use of carotenoids in foods is limited due to their poor solubility in water-rich matrices, and the nanoencapsulation emerges as an alternative to allowing the solubilization and to protect the carotenoids against degradation. The aims of this study were to produce, by the interfacial deposition of the preformed polymer, to characterize, and evaluate the stability of nanocapsules obtained from a blend of $\beta$-carotene, $\alpha$-carotene, and lutein (BALNs) and nanocapsules of synthetic $\beta$-carotene (BNs). The encapsulation efficiency, transmission electron microscopy, and the logarithm of the distribution of the coefficient of the BALNs and BNs, with $26 \mu \mathrm{g} / \mathrm{mL}$ of carotenoids, were performed after preparation. During 100 days of storage $\left(4{ }^{\circ} \mathrm{C}\right)$ for the
\end{abstract}

Alessandro de Oliveira Rios

alessandro.rios@ufrgs.br

1 Departamento de Ciência e Tecnologia de Alimentos, Universidade Federal de Pelotas (UFPel), Campus Universitário s/n, Pelotas, RS CEP 96010-900, Brazil

2 Empresa Brasileira de Pesquisa Agropecuária (Embrapa), Rodovia BR 392, Km 78, $9^{\circ}$ Distrito, Monte Bonito, Pelotas, RS CEP 96010-971, Brazil

3 Programa de Pós-Graduação em Ciências Farmacêuticas, Faculdade de Farmácia, Universidade Federal do Rio Grande do Sul (UFRGS), Porto Alegre, RS CEP 90610-000, Brazil

4 Departamento de Química Orgânica, Instituto de Química, Universidade Federal do Rio Grande do Sul (UFRGS), Av. Bento Gonçalves, n. 9500, Porto Alegre, RS CEP 91501-970, Brazil

5 Instituto de Química, Instituto de Química, Universidade Federal do Rio Grande do Sul (UFRGS), Av. Bento Gonçalves, n. 9500, Porto Alegre, RS CEP 91501-970, Brazil

6 Instituto de Ciência e Tecnologia de Alimentos, Universidade Federal do Rio Grande do Sul (UFRGS), Av. Bento Gonçalves, n. 9500, Porto Alegre, RS CEP 91501-970, Brazil
BALNs and BNs, the carotenoids retention, hydrogen potential, color, particle diameter, and the zeta potential were analyzed. The $z$-average and zeta potential after 100 days of storage for the BALNs and BNs were, respectively, 166.53 $\pm 4.71 \mathrm{~nm} /-18.37 \pm 2.06 \mathrm{mV}$ and $190.90 \pm 7.87 \mathrm{~nm} /-9.08$ $\pm 1.23 \mathrm{mV}$. At the end of storage, the $\beta$-carotene content was $67.62 \pm 7.77 \%$ (BALNs) and $11.69 \pm 1.65 \%$ (BNs). The $\beta$ carotene retention in the BALNs was higher than in the BNs probably due to the synergism that occurs among the compounds. Regardless of the decrease in the $\mathrm{pH}$ values and the $\mathrm{b}^{*}$ coordinate, the formulations of the BALNs and BNs were considered physically stable during the storage. Nevertheless, beyond the physical stability, the BALNs presented a satisfactory carotenoid retention at end of storage.

Keywords Carotenoids · Nanoencapsulation · Production . Stability

\section{Introduction}

Carotenoids are yellow, orange, or red color pigments synthesized by photosynthetic organisms through the isoprenoid or terpenoid pathway (Mínguez-Mosquera et al. 2007; AparicioRuiz et al. 2011). The principal carotenoids found in food matrices are $\beta$-carotene, $\alpha$-carotene, $\beta$-cryptoxanthin, lycopene, lutein, and violaxanthin (Rodriguez-Amaya et al. 2008). These pigments are found worldwide, and Brazil is one of the countries with the greatest diversity and content of carotenoids, due to this country's possession of areas with tropical and subtropical climate, which provides an increase in the biosynthesis of carotenoids.

Carrots (Daucus carota L.) are an excellent source of carotenoids, since when compared with other roots such as sweet potato, the carrot has a higher $\beta$-carotene content 
$(48.20 \mu \mathrm{g} / \mathrm{g})$ than sweet potato $(8.60 \mu \mathrm{g} / \mathrm{g})$ (Zakaria-Rungkat et al. 2000). The carotenoid content varies widely between different varieties of carrots (high orange, orange, purple, red, yellow, and a white color), but in those with an orange peel there are $12800 \pm 3300 \mu \mathrm{g} / \mathrm{g}$ w.b. ( $\beta$-carotene), 2200 $\pm 800 \mu \mathrm{g} / \mathrm{g}$ w.b. ( $\alpha$-carotene), and $260 \pm 80 \mu \mathrm{g} / \mathrm{g}$ w.b. (lutein), these results are expressed on a wet basis (Surles et al. 2004).

Several epidemiological studies have been conducted with carotenoids, and these confirm that an adequate intake of carotenoids through food or supplements reduces considerably the risk of chronic and degenerative diseases (Fiedor and Burda 2014). These health benefits provided by carotenoids are due to their high antioxidant activity, which are responsible for scavenge the singlet molecular oxygen and the peroxyl radicals (Stahl and Sies 2003).

Besides the antioxidant activity, some carotenoids like $\beta$-carotene, $\alpha$-carotene, and $\beta$-cryptoxanthin that have $\beta$-ionone rings, are well-known for provitamin A activity, which also provides health benefits (Niizu and Rodriguez-Amaya 2005). Among these carotenoids, the $\beta$-carotene has the greatest potential for provitamin A activity (U.S. Institute of Medicine 2001).

The above-described properties of carotenoids make them good ingredients for human consumption, in view of consumer awareness about the relationship between diet and health has increased. Therefore, in recent years, the food industry has been aiming to increase the production of foods that promote health. However, there is an obstacle with the application of carotenoids in food products, because the carotenoids present poor water solubility, a high melting point, chemical instability, and a low bioavailability (Qian et al. 2012).

In this context, the encapsulation technique emerges as an alternative to allow the solubilization of carotenoids in watersoluble food and to protect these against thermal and photodegradation. One of the segments of encapsulation is the nanoencapsulation, which is characterized by entrap compounds, for instance, bioactive compounds into carrier materials, the dimensions of this system are in a nano-scale (Fathi et al. 2014).

Some works give evidence of the application of fat-soluble compounds in foods with a high water content, such as the work developed by Ilyasoglu and El (2014), where the nanoencapsulation of the acids eicosapentaenoic (EPA) and docosahexaenoic (DHA), present in fish oil, with sodium caseinate and gum arabic made possible the dispersion of EPA and DHA in mixed fruit juice. The EPA and DHA were dissolved previously in ethanol and added to the proteinpolysaccharide solutions according to the method described by Zimet and Livney (2009).

In recent years, studies on nanocapsules of the single bioactive compounds have been performed, for instance, studies on bixin, lutein, and $\beta$-carotene. Lobato et al. (2013) developed lipid-core nanocapsules (LCN) of bixin surrounded by

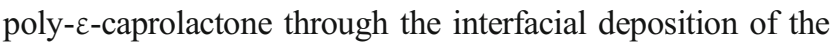
preformed polymer technique. They concluded that the encapsulation of bixin provided less degradation of this compound when compared to free bixin, besides a soluble nanocapsule suspension. Jin et al. (2009) produced nanocapsules of lutein by the supercritical antisolvent precipitation method, where the wall material used was hydroxypropylmethyl cellulose phthalate (HPMCP). The mean diameter of the lutein nanocapsules was, being nearly spherical, in the range of 163-219 $\mathrm{nm}$. The $\beta$-carotene was encapsulated by Yi et al. (2015) using sodium caseinate (SC), whey protein isolate (WPI), and soybean protein isolate (SPI) as wall material by the homogenization-evaporation technique forming, respectively, nanoparticles of 78, 90, and $370 \mathrm{~nm}$ of diameter. These nanoparticles showed to decrease peroxyl radical oxidation in Caco-2 cells. Finally, they concluded that the in vitro release of $\beta$-carotene was greater for SC and WPI, although WPI was resistant to the digestion of pepsin.

It is possible to observe that some studies have been conducted with the nanoencapsulation of carotenoids, but these are in an isolated form. However, it is known that a vegetablebased diet is beneficial to health due to the synergic effect of its components (Linnewiel-Hermoni et al. 2015). Then, this work aimed to produce by the method of interfacial deposition of the preformed polymer LCN from a blend of $\beta$-carotene, $\alpha$-carotene, and lutein from "Baltimore" carrots and LCN from synthetic $\beta$-carotene. It was also the aim to characterize and evaluate the stability of them during cold storage $\left(4^{\circ} \mathrm{C}\right)$ for a period of 100 days.

\section{Material and Methods}

\section{Materials}

The poly- $\varepsilon$-caprolactone polymer $(\mathrm{PCL})(\mathrm{Mw}=80,000)$ and sorbitan monostearate were purchased from Sigma (St. Louis, MO, USA). Triglycerides of the capric and caprylic acids (TCCA) and polysorbate 80 were purchased from Delaware (Porto Alegre, Brazil). All other chemicals and solvents were of analytic or pharmaceutical grade. The vegetal material ("Baltimore" carrots) was obtained in a local market in Porto Alegre city, Brazil.

\section{Carotenoids Profile of "Baltimore" Carrots}

The carotenoids profile of carrots was performed according to Mercadante and Rodriguez-Amaya (1998) through the extraction of these compounds with cold acetone and subsequent saponification with $10 \mathrm{~g} \mathrm{~L}^{-1} \mathrm{KOH}$ in a methanol solution. The samples were maintained overnight at rest and after them were washed and concentrated in a rotaryevaporator (Fisatom model 801/802, São Paulo, SP, Brazil). Then, the final extract was injected in the highperformance liquid chromatograph (HPLC). 


\section{Ethanol Extract of Carotenoids}

"Baltimore" carrots ( $1 \mathrm{~g})$, absolute ethanol ( $\geq 99.5 \%)$, and a water bath at $25^{\circ} \mathrm{C}$ were used to obtain the ethanol extract of $\beta$-carotene, $\alpha$-carotene, and lutein. The extraction of these carotenoids from "Baltimore" carrots was performed using a $2^{3}$ factorial design with axial points (Table 1), which generated 17 assays, to examine the single effect and the interactions of the effects between the solvent volume $(\mathrm{x} 1, \mathrm{~mL})$, number of extractions $(x 2)$, and the extraction time (x3, min). During the extraction, the ethanol extract was filtered and finally concentrated up to $10 \mathrm{~mL}$ under a reduced pressure in a rotaryevaporator (Fisatom model 801/802, São Paulo, SP, Brazil).

\section{Preparation of the LCN}

The LCN from a blend of $\beta$-carotene, $\alpha$-carotene, and lutein (BALNs) and the LCN from synthetic $\beta$-carotene (BNs) were produced by the interfacial deposition of the preformed polymer method according to Venturini et al. (2011), with some modifications in the amounts of acetone and ethanol. The $\mathrm{LCN}$ are composed of two phases, the organic and aqueous phases. In the organic phase were used the PCL $(250 \mathrm{mg})$, sorbitan monostearate $(95 \mathrm{mg})$, TCCA $(400 \mu \mathrm{L})$, acetone $(135 \mathrm{~mL})$, ethanol extract $(15 \mathrm{~mL})$ of $\beta$-carotene, $\alpha$-carotene and lutein from carrots in the BALNs and ethanol extract $(15 \mathrm{~mL})$ of synthetic $\beta$-carotene in the BNs. This amount of ethanol extract was established so that the final formulation of the $\mathrm{LCN}$ possessed a concentration of $26 \mu \mathrm{g} / \mathrm{mL}$ of the sum of carotenoids ( $\beta$-carotene, $\alpha$-carotene and lutein) in the BALNs and $26 \mu \mathrm{g} / \mathrm{mL}$ of $\beta$-carotene in the BNs.

In the aqueous phase, polysorbate $80(192.50 \mathrm{mg})$ and ultrapure water $(132.50 \mathrm{~mL})$ were used. The organic phase was maintained under a magnetic stirring for $40 \mathrm{~min}$ at $40^{\circ} \mathrm{C}$, until there was a complete dissolution of the PCL, sorbitan monostearate, and TCCA. At the same time, the aqueous phase was maintained under a magnetic stirring at $25{ }^{\circ} \mathrm{C}$. Then, the organic phase was injected into an aqueous, where it remained under magnetic stirring for $10 \mathrm{~min}$ at $25{ }^{\circ} \mathrm{C}$. Afterward, each formulation was concentrated under reduced pressure until it reached a final volume of $25 \mathrm{~mL}$.

Table 1 Factors and levels used in the $2^{3}$ factorial design study

\begin{tabular}{llllll}
\hline Factors & \multicolumn{2}{l}{ Levels } & & & \\
\cline { 2 - 6 } & -1.68 & -1 & 0 & +1 & +1.68 \\
\hline Number of extractions & 2 & 3 & 4 & 5 & 6 \\
Extraction time & 5 & 15 & 30 & 45 & 55 \\
Solvent volume & 23 & 30 & 40 & 50 & 57 \\
\hline
\end{tabular}

\section{Encapsulation Efficiency}

The carotenoids retention in the aqueous phase of the LCN suspension (BALNs and BNs) was evaluated through of the injection of filtrate in the HPLC. This filtrate was obtained by an ultrafiltration/centrifugation method of an aliquot $(400 \mu \mathrm{L})$ of the LCN using an Ultrafree-MC ${ }^{\circledR}(10,000 \mathrm{MW}$, Millipore, Bedford, USA) in a centrifuge ( $15 \mathrm{~min}$ at $1690 \times \mathrm{g}$ ). The encapsulation efficiency was determined through dividing the difference between the total content of carotenoids in the LCN and the carotenoids content in the aqueous phase by the total content of carotenoids and multiplying the results by 100 (Venturini et al. 2011).

\section{Carotenoids Retention}

The retention of $\beta$-carotene, $\alpha$-carotene, and lutein in the BALNs and $\beta$-carotene in the BNs was evaluated through the extraction from the LCN. The LCN $(500 \mu \mathrm{L})$ was added to acetonitrile $(2.5 \mathrm{~mL})$ and sonicated by an ultrasound (30 min), then dried in compressed $\mathrm{N}_{2}$, diluted with methyl tert-butyl ether $(1 \mathrm{~mL})$, and injected in the HPLC (Lobato et al. 2013).

\section{High-Performance Liquid Chromatography}

The carotenoids profile of the "Baltimore" carrots and of the ethanol extract from carrots, the carotenoids retention in the LCN, and the encapsulation efficiency of the LCN were determined through the HPLC (Agilent series 1100, Santa Clara, CA, USA), using an online degasser, a quaternary pump, and an automatic injector coupled to a $\mathrm{C} 30$ polymeric column YCM $(250 \times 4.6 \mathrm{~mm}$ i.d., $3-\mu \mathrm{m}$ particle size $)$ at $33{ }^{\circ} \mathrm{C}$ (Mercadante and Rodriguez-Amaya 1998). Data acquisition and processing were performed using the ChemStation ${ }^{\circledR}$ software.

The gradient of the mobile phase was composed of water, methanol, and methyl tert-butyl ether, starting at a ratio of 5:90:5 and reaching 0:95:5 in $12 \mathrm{~min}, 0: 89: 11$ in $25 \mathrm{~min}$, 0:75:25 in $40 \mathrm{~min}$, and 0:50:50 in $60 \mathrm{~min}$. The flow rate of the mobile phase gradient was $1 \mathrm{~mL} / \mathrm{min}$, the injection volume was $5 \mu \mathrm{L}$ with $33^{\circ} \mathrm{C}$ for the injection temperature.

The chromatograms were processed at an absorption wavelength of $470 \mathrm{~nm}$. For the quantification of $\beta$-carotene, $\alpha$ carotene, and lutein, a calibration curve with a determination coefficient $\left(R^{2}\right)$ greater than 0.99 was used. The samples were filtered before the injection in the HPLC $(0.45 \mu \mathrm{m}$ with a modified PTFE membrane for the aqueous and organic solvents, Millipore, Barueri, SP, Brazil). All the solvents used in the HPLC were of chromatographic grade and were previously filtered through a Millipore vacuum filtration system using a $0.22-\mu \mathrm{m}$ membrane for organic solvents (Millipore, Barueri, SP, Brazil). 


\section{Hydrogen Potential (pH)}

The $\mathrm{pH}$ of the BALNs and BNs was performed at $25^{\circ} \mathrm{C}$ with a potentiometer Quimis ${ }^{\circledR}$, Q400A, Diadema, São Paulo.

\section{Samples Color}

The color of the samples was determined by the objective method, with a three-parameter reading system, the CIE $\mathrm{La}^{*} \mathrm{~b}^{*}$, proposed by the Commission Internacionale I'Eclairage (CIE). This analysis was performed using the colorimeter Konica Minolta ${ }^{\circledR}$, CR-400 model, Singapore, where $\mathrm{L}$ expresses lightness and $\mathrm{a}^{*}$ and $\mathrm{b}^{*}$ are responsible for chromaticity. The $\mathrm{L}, \mathrm{a}^{*}$, and $\mathrm{b}^{*}$ parameters were evaluated using the illuminant $\mathrm{D}_{65}$ and a viewing angle of $0^{\circ}$.

\section{Particle Diameter and Zeta Potential}

The volume-weighted mean diameter $\left(\mathrm{D}_{4,3}\right)$ of the BALNs and BNs was measured by laser diffraction (LD, Mastersizer $200{ }^{\circledR}$ 5.61, Malvern Instruments, UK). Span values were determined also through the Mastersizer $2000^{\circledR} 5.61$ software.

The dynamic light scattering (DLS) was also used to evaluate the mean diameter ( $z$-average) and the polydispersity in$\operatorname{dex}(\mathrm{PDI})$ at $25^{\circ} \mathrm{C}$ (Zetasizer ${ }^{\circledR}$ nano-ZS, Malvern, UK). This is one of the most common methodologies to measure the diameter of the nanocapsules, based on the principle of particles in Brownian motion.

The zeta potential is an analysis that allows knowledge of the total charge that a particle acquires in a particular medium. This parameter was done by electrophoretic mobility (Zetasizer ${ }^{\circledR}$ nano-ZS, Malvern, UK).

\section{TEM}

The morphological analysis of the BALNs and BNs was performed by TEM (Jeol, JEM 1200 Exll, Electron Microscopy Center, UFRGS, Brazil). The LCN samples were diluted in ultrapure water $(1: 10 \mathrm{v} / \mathrm{v})$, where one drop of this dilution was deposited on a grid (Formvar-carbon support films mesh 400), and after $5 \mathrm{~min}$, a drop of uranyl acetate $(2 \% \mathrm{w} / \mathrm{v})$ was also deposited. The TEM analysis was performed in $80 \mathrm{kv}$.

\section{$\log D$}

To determine the $\log \mathrm{D}$ in the function of the $\mathrm{pH}$ and chemical structure of the samples, the software ACD Log D 6.0 (Advanced Chemistry Development, Inc., Toronto, Canada) was used.

The carotenoids retention, $\mathrm{pH}$, color, particle diameter, and zeta potential were evaluated weekly for 21 days, after this period, the evaluation was taken after 60 and 100 days of storage at $4{ }^{\circ} \mathrm{C}$. Then, the encapsulation efficiency, the
TEM, and calculation of $\log \mathrm{D}$ were made immediately after the preparation of the formulations.

\section{Experimental Design and Statistical Analysis}

The formulations of the BALNs and BNs were performed in triplicate, and the experimental design was completely randomized. These formulations were stored under cold conditions $\left(4 \pm 1{ }^{\circ} \mathrm{C}\right)$ with relative humidity of the $85 \%$ in hermetically sealed amber bottles. For the analysis of variance (ANOVA) and Tukey test $(p \leq 0.05)$ of the data of the $2^{3}$ factorial experimental design it was used Statistica 12 software. The software used for analysis of other data was SAS 8.0, and Sigma Plot 12.0 was used for the production of the graphics contained in the figures. All data represented in the figures were the means of three replicates \pm the standard deviation. The effect of the LCN formulation (BALNs or BNs) and the storage time $(0,7,14,21,60$, and 90 days) were evaluated. The data were subjected to an analysis of variance (ANOVA) and to the mean Tukey test $(p \leq 0.05)$.

\section{Results and Discussion}

\section{Carotenoids Profile of "Baltimore" Carrots}

The carotenoids profile of "Baltimore" carrots is in Fig. 1. Comparing the retention times of the standards and samples (three replicates) that were injected, it is possible to assert that in Fig. 1, the numbers 1, 2, and 3 correspond to lutein, $\alpha$ carotene, and $\beta$-carotene, respectively. The average content of carotenoids in the extract of carrots was $846.82 \mu \mathrm{g} / 100 \mathrm{~g}$ (lutein), $11935.07 \mu \mathrm{g} / 100 \mathrm{~g}$ ( $\alpha$-carotene), and $41499.44 \mu \mathrm{g} /$ $100 \mathrm{~g}(\beta$-carotene).

\section{Ethanol Extract of Carotenoids}

Several studies do not use food grade solvents for the extraction of carotenoids from vegetables, as shown in a work conducted by Rebecca et al. (2014), where one mixture of hexane

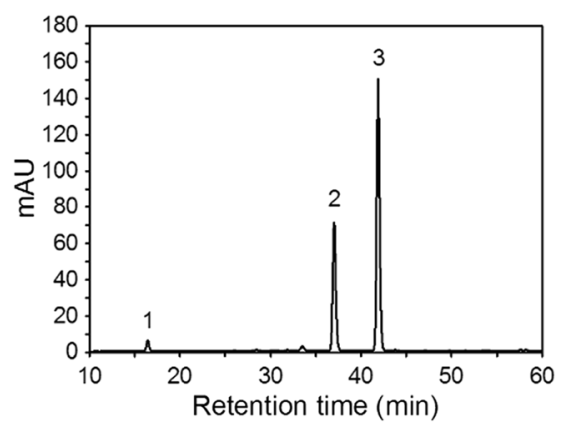

Fig. 1 Carotenoids profile of "Baltimore" carrots. 1 lutein, $2 \alpha$-carotene, and $3 \beta$-carotene 
and acetone in the ratio of 1:1 was used to extract carotenoids from red capsicum, yellow capsicum, red spinach, carrot, broccoli, and beetroot. However, this study used a solvent that is generally recognized as safe (GRAS), ethanol, which is also considered environmentally friendly and not toxic to human health (Bucić-Kojić et al. 2009).

With a mathematical model study, Das and Bera (2013) sought ideal conditions for the $\beta$-carotene extraction from raw carrots. Among different solvents (ethanol, petroleum ether, n-hexane, and ethyl acetate), temperatures (30, 40, and $\left.50{ }^{\circ} \mathrm{C}\right)$ and the carrot-solvent ratio $(1: 5$ to $1: 60)$, they concluded that when ethanol is used, at $40^{\circ} \mathrm{C}$ and a solid-solvent ratio of $1: 40$, a greater $\beta$-carotene content is achieved.

Mustafa et al. (2012) aimed to optimize the conditions for the extraction of carotenoids ( $\beta$-carotene and $\alpha$-carotene) from carrots with solvents at elevated temperatures $(60$ $\left.180{ }^{\circ} \mathrm{C}\right)$ and different extraction times $(2-10 \mathrm{~min})$ at 50 bars of pressure. High pressure and temperatures provide less spent of solvent and shorter extraction times. They found that the $60{ }^{\circ} \mathrm{C}$ and 5 -min pre-heating plus 10 -min extraction $(5 \times 2 \mathrm{~min})$ at 50 bars were the most suitable conditions for the extraction of $\beta$-carotene and $\alpha$-carotene from carrots. Thus, the extraction of carotenoids from carrots depends strongly on the applied conditions.
It is observed through the data presented above, that several factors influence the efficiency of obtaining carotenoids. This work tested by the $2^{3}$ factorial design, the influence of the solvent volume $(\times 1)$, number of extractions $(\times 2)$, and extraction time $(\times 3)$ on the extraction of carotenoids $(\beta$-carotene, $\alpha$ carotene, and lutein) from "Baltimore" carrots with the ethanol at $25^{\circ} \mathrm{C}$.

By the analysis of variance (ANOVA) of the experimental design, it was observed that the extraction time presented a significant $p$ value for the three carotenoids, $\beta$-carotene $(p \leq 0.02), \alpha$-carotene $(p \leq 0.05)$, and lutein $(p \leq 0.05)$ in the yield. The effects were positive for all carotenoids, and the interaction of the number of extractions and extraction time was also significant for the yield of $\beta$-carotene $(p \leq 0.008), \alpha$-carotene $(p \leq 0.011)$, and lutein $(p \leq 0.031)$. Because the variable extraction time had significant and positive effects for all carotenoids, an increase in the extraction time increases the efficiency of the carotenoids extraction; thus, 17th experiment $(55 \mathrm{~min} ; 40 \mathrm{~mL}$ of ethanol; 4 extractions) may be used for a higher yield. Table 2 shows the carotenoids retention achieved with the 17 experiments.

With the 17 experiments carried out through the $2^{3}$ fullfactorial, the behavior of the system for $\beta$-carotene, $\alpha$-carotene, and lutein was fitted to second-order equations:

$$
\begin{aligned}
& \beta-\text { carotene }=26771.47+2554.29 \times 2+4784.25 \times 3-2586.52 \times 3^{2}-3404.20 \times 1 \times 2 \\
& -4450.14 \times 1 \times 3-7322.31 \times 2 \times 3 \\
& \alpha-\text { carotene }=9017.70+1033.97 \times 1+640.37 \times 1^{2}+1665.57 \times 3-1125.03 \times 3^{2} \\
& -2378.37 \times 1 \times 3-3018.98 \times 2 \times 3 \\
& \text { lutein }=782.17-40.83 \mathrm{x}^{2}+36.59 \times 2^{2}+119.17 \times 3-131.48 \times 3^{2}-194.48 \times 1 \times 3 \\
& -178.26 \times 2 \times 3
\end{aligned}
$$

Comparing the carotenoids profile in the "Baltimore" carrots performed by the traditional method (with saponification) and by the optimized method (using ethanol at $25^{\circ} \mathrm{C}$ and varying the solvent volume, number of extraction and extraction time), it was observed that the recovery perceptual of $\beta$ carotene, $\alpha$-carotene, and lutein with the optimized method was $70.15,82.55$, and $80.73 \%$, respectively.

\section{Encapsulation Efficiency}

After the preparation of the formulations of the BALNs and $\mathrm{BNs}$, then the encapsulation efficiency analysis was performed by the equation $((26.00-0.0919) / 26.00) \times 100$ for the BALNs and $((26.00-0.0653) / 26.00) \times 100$ for the BNs. Then, the encapsulation efficiency was $99.65 \%$ (BALNs) and $99.75 \%$ (BNs), which means that the most of the carotenoids added to the formulations were entrapped in the core of the nanocapsules. Lobato et al. (2013), using the same encapsulation technique of this study, obtained an encapsulation efficiency of $100 \%$ in the nanocapsules of bixin. This high encapsulation rate achieved by studies that use interfacial deposition of the preformed polymer method is probably due to the presence of the TCCA in the core of the nanocapsules, which facilitates the solubilization of carotenoids.

\section{Carotenoids Retention}

Concerning carotenoids retention (\%) in the BALNs (Fig. 2a), it was observed that $67.62 \pm 7.77 \%$ ( $\beta$-carotene), 64.16 $\pm 4.85 \%$ ( $\alpha$-carotene), and $56.55 \pm 3.65$ (lutein) remained present in the formulations after 100 days of storage $\left(4{ }^{\circ} \mathrm{C}\right)$. Whereas in the nanoemulsions of $\beta$-carotene stabilized by modified starch (CAPSUL) with an average molecular weight of $8.29 \pm 0.0210^{4} \mathrm{~g} / \mathrm{mol}$, the $\beta$-carotene retention (\%) was $64.36 \pm 0.40 \%$ after 30 days of storage $\left(4^{\circ} \mathrm{C}\right.$ ) (Liang et al. 2013). Oil-in-water nanoemulsions of $\beta$-carotene stabilized by a globular protein ( $\beta$-lactoglobulin) stored for 14 days at $5,20,37$, and $55^{\circ} \mathrm{C}$ arrested $56.74,44.05,6.75$, and $0 \%$ of $\beta$ - 
Table 2 Carotenoids retention $(\beta$-carotene, $\alpha$-carotene and lutein) in the ethanol extract from the 'Baltimore' carrots

\begin{tabular}{lllll}
\hline Experiment & $\begin{array}{l}\beta \text {-carotene content } \\
(\mu \mathrm{g} / 100 \mathrm{~g})\end{array}$ & $\begin{array}{l}\alpha \text {-carotene content } \\
(\mu \mathrm{g} / 100 \mathrm{~g})\end{array}$ & $\begin{array}{l}\text { Lutein content } \\
(\mu \mathrm{g} / 100 \mathrm{~g})\end{array}$ & $\begin{array}{l}\text { Total carotenoids } \\
(\mu \mathrm{g} / 100 \mathrm{~g})\end{array}$ \\
\hline 1 & 16054.16 & 4772.15 & 511.13 & 21337.44 \\
2 & 22962.88 & 8714.61 & 630.01 & 32307.50 \\
3 & 29570.03 & 9596.37 & 704.78 & 39871.18 \\
4 & 25977.49 & 10259.57 & 750.97 & 36988.03 \\
5 & 33005.68 & 11960.12 & 1065.55 & 46031.35 \\
6 & 27321.28 & 9231.31 & 722.89 & 37275.48 \\
7 & 28184.07 & 8831.86 & 830.11 & 37846.03 \\
8 & 19384.12 & 6652.85 & 559.92 & 26596.89 \\
9 & 29086.23 & 10413.15 & 895.21 & 40394.59 \\
10 & 24080.12 & 7621.31 & 610.64 & 32312.07 \\
11 & 25664.81 & 7814.56 & 791.86 & 34271.23 \\
12 & 22663.22 & 7764.62 & 719.31 & 31147.15 \\
13 & 31940.80 & 12143.39 & 923.67 & 45007.86 \\
14 & 23562.70 & 8881.68 & 909.92 & 33354.29 \\
15 & 31284.39 & 10411.45 & 793.99 & 42489.83 \\
16 & 17616.48 & 5072.87 & 545.89 & 23235.23 \\
17 & 29110.23 & 9852.48 & 683.66 & 39646.37 \\
\hline
\end{tabular}

carotene, respectively (Qian et al. 2012). Some factors may explain this higher decrease of $\beta$-carotene content in the nanoemulsions than in the BALNs of the present work, among these, the high surface area and oxygenation of the nanoemulsions could be highlighted, which occurs during the homogenization step (Silva et al. 2011). Thus, BALNs are able to keep higher levels of $\beta$-carotene than nanoemulsion during cold storage.

In accordance with Tan and Nakajima (2005), the $\beta$ carotene nanodispersions of the organic/aqueous phase ratio of $2: 8$ and produced using different homogenizing conditions (pressure and number of cycles), presented a $\beta$-carotene retention (\%) of 56.00 (60 Mpa and 1 cycle) and of 32.10 (140 Mpa and 3 cycles) after 84 days of storage $\left(4^{\circ} \mathrm{C}\right)$. Observing the results of this study, it is apparent that the conditions under which the nanocapsules are made directly influence the retention of these compounds. However, the nanodispersions of $\beta$ carotene produced by the solvent displacement method with different emulsifiers (sodium caseinate, tween 20, decaglycerol monolaurate, and sucrose fatty acid ester) presented a higher $\beta$-carotene retention (\%) at 56 days of storage $\left(4{ }^{\circ} \mathrm{C}\right)$ when done with sodium caseinate. In this context, it can be affirmed that the choice of a suitable emulsifier is important for a good stability of nanodispersions (Yin et al. 2009).

Observing Fig. 2b, which compares the formulations of the BALNs and BNs in relation to $\beta$-carotene retention, it is noted that the remains of $\beta$-carotene after 100 days of storage were $67.62 \pm 7.77 \%$ (BALNs) and $11.69 \pm 1.65 \%$ (BNs). At 100 days of storage, the $\beta$-carotene content in the BALNs was about six times higher than in the BNs. This was probably due to the synergistic effect between the compounds. In contrast to that, it has been elucidated for one study of natural and synthetic $\beta$-carotene nanoparticles coated with polylactic acid by the water-in-oil solvent displacement method (Cao-Hoang et al. 2011). In this work, it is noteworthy that the natural $\beta$ carotene degraded faster than the synthetic $\beta$-carotene contained in the nanoparticles over the $23 \mathrm{~h}$ of storage, suggesting the intrinsic presence of reactive oxygen species in
Fig. 2 Carotenoids retention (\%) in the BALNs (a) and $\beta$-carotene retention $(\%)$ in the BALNs and $\mathrm{BNs}(\mathbf{b})$ over the storage time $\left(4{ }^{\circ} \mathrm{C}\right)$
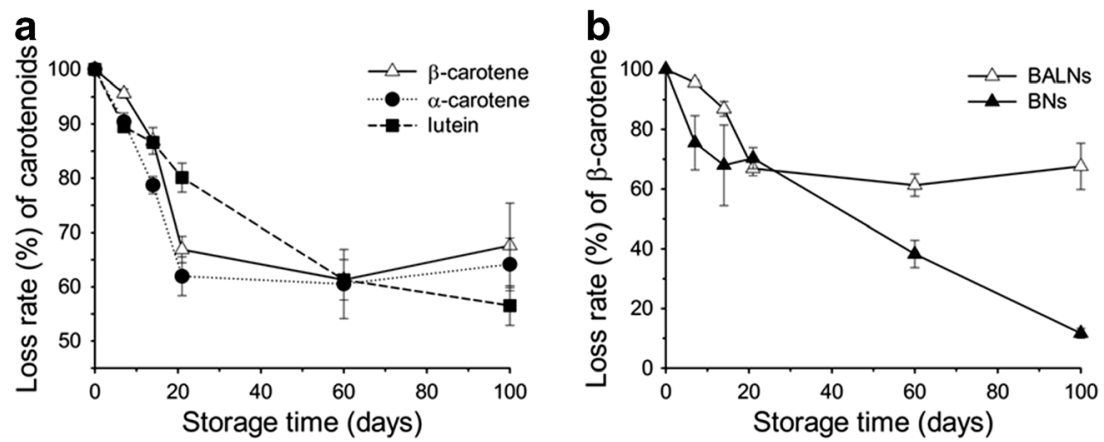
natural $\beta$-carotene, which can confer prooxidant activities to this carotenoid.

\section{pH}

The $\mathrm{pH}$ was statistically influenced by storage time and formulation factors (Table 3$)$. In all the days of storage $(0,7,14$, 21,60 , and 100), the formulations of the BALNs presented lower $\mathrm{pH}$ values than the $\mathrm{BNs}$. This fact is probably due to the composition of the ethanol extract from the carrots that is different than those made with synthetic $\beta$-carotene. The initial $\mathrm{pH}$ of the ethanol extract from carrots and from synthetic $\beta$-carotene was, respectively, $3.45 \pm 0.01$ and $5.66 \pm 0.06$.

During the cold storage, the $\mathrm{pH}$ values of the formulations of the BALNs and BNs declined from $3.17 \pm 0.03$ to 2.95 \pm 0.05 at day 100 (BALNs) and from $5.50 \pm 0.12$ to 4.25 \pm 0.20 at day 100 (BNs). Santos et al. (2015) conducted a study with the same technique of the present work for the production of the nanocapsules, they worked with lycopeneloaded lipid-core nanocapsules $(85 \mu \mathrm{g} / \mathrm{mL})$ stored at $25{ }^{\circ} \mathrm{C}$ and also found a reduction in $\mathrm{pH}$ values from $6.01 \pm 0.04$ to $5.60 \pm 0.02$ during the storage ( 28 days).

The wall (polymer) degradation contributes to the decrease of $\mathrm{pH}$ values due to the release of acidic species from the

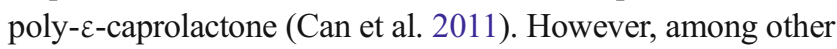
polymers, the PCL is one that provides a minimization of the medium acidification, so it is used in blends with other polymers such as poly(lactic acid) (Liao et al. 2008).

\section{Samples Color}

The data for samples color are shown in Table 3. The BALNs and BNs formulations initially exhibited a yellow color, with the following CIELAB coordinates of $\mathrm{L}=72.16 \pm 0.05$, $\mathrm{a}^{*}=-5.83 \pm 0.05, \mathrm{~b}^{*}=44.87 \pm 0.11$ and $\mathrm{L}=74.91 \pm 0.09$, $a^{*}=-2.10 \pm 0.02, b^{*}=44.00 \pm 1.99$, respectively. Lobato et al. (2013) observed color differences between the nanoencapsulated bixin and the free bixin, nanoencapsulated bixin presented a higher brightness $(\mathrm{L})$, a yellow color $\left(\mathrm{b}^{*}\right)$, and a smaller red color $\left(a^{*}\right)$ than the free bixin. This higher brightness is due to an opacity promoted by the PCL polymer used in the organic phase of nanocapsules.

An increase in the $\mathrm{L}$ values was observed in the BALNs and BNs from the 21 st and 60 th day of storage $\left(4^{\circ} \mathrm{C}\right)$, respectively. This promotion of clarity is due to a loss of carotenoids by both formulations. In all days of storage $(0,7,14,21,60$, and 100$)$, the BNs $(75.10 \pm 0.91)$ presented higher $\mathrm{L}$ average values than the BALNs $(72.86 \pm 0.55)$.

The $\mathrm{a}^{*}$ values did not practically varied during the storage time of the BALNs, but in the formulations of the BNs, occurred a statistical difference among $\mathrm{a}^{*}$ values from the 60th day. And from 0 to 21 days of storage, the BNs presented higher $\mathrm{a}^{*}$ values than the BALNs. This can be explained
Table 3 The effect of nanocapsules formulation (BALNs and BNs) and storage time $\left(0,7,14,21,60\right.$, and 90 days) at $4{ }^{\circ} \mathrm{C}$ on potential zeta, $\mathrm{pH}$, and color $\left(\mathrm{L}, \mathrm{a}^{*}, \mathrm{~b}^{*}\right)$ of the nanocapsules

\begin{tabular}{|c|c|c|}
\hline \multirow[t]{2}{*}{ Storage time (days) } & \multicolumn{2}{|l|}{ Formulation } \\
\hline & BALNs & $\mathrm{BNs}$ \\
\hline & $\mathrm{pH}$ & $\mathrm{pH}$ \\
\hline 0 & $3.17 \pm 0.03 \mathrm{~B} \mathrm{a}$ & $5.50 \pm 0.12 \mathrm{~A} \mathrm{~b}$ \\
\hline 7 & $3.11 \pm 0.01 \mathrm{~B} \mathrm{ab}$ & $5.91 \pm 0.02 \mathrm{~A} \mathrm{a}$ \\
\hline 14 & $3.05 \pm 0.01 \mathrm{~B} \mathrm{bc}$ & $5.36 \pm 0.13 \mathrm{~A} \mathrm{~b}$ \\
\hline 21 & $2.98 \pm 0.02 \mathrm{~B} \mathrm{~cd}$ & $5.28 \pm 0.03 \mathrm{~A} \mathrm{~b}$ \\
\hline 60 & $2.91 \pm 0.03 \mathrm{~B} \mathrm{~d}$ & $4.53 \pm 0.16 \mathrm{~A} \mathrm{c}$ \\
\hline \multirow[t]{2}{*}{100} & $2.95 \pm 0.05 \mathrm{~B} \mathrm{~d}$ & $4.25 \pm 0.20 \mathrm{~A} \mathrm{c}$ \\
\hline & Zeta potential & Zeta potential \\
\hline 0 & $-23.93 \pm 0.55 \mathrm{~B} \mathrm{~b}$ & $-10.33 \pm 2.01 \mathrm{~A} \mathrm{a}$ \\
\hline 7 & $-22.67 \pm 2.48 \mathrm{~B} \mathrm{ab}$ & $-9.17 \pm 0.54 \mathrm{~A} \mathrm{a}$ \\
\hline 14 & $-22.87 \pm 1.63 \mathrm{~B} \mathrm{~b}$ & $-9.68 \pm 0.48 \mathrm{~A} \mathrm{a}$ \\
\hline 21 & $-23.63 \pm 1.45 \mathrm{~B} \mathrm{~b}$ & $-9.12 \pm 1.23 \mathrm{~A} \mathrm{a}$ \\
\hline 60 & $-22.50 \pm 0.10 \mathrm{~B} \mathrm{ab}$ & $-13.80 \pm 3.21 \mathrm{~A} \mathrm{a}$ \\
\hline \multirow[t]{2}{*}{100} & $-18.37 \pm 2.06 \mathrm{~B} \mathrm{a}$ & $-9.08 \pm 1.23 \mathrm{~A} \mathrm{a}$ \\
\hline & Polydispersity index & Polydispersity index \\
\hline 0 & $0.09 \pm 0.01 \mathrm{~A} \mathrm{a}$ & $0.08 \pm 0.02 \mathrm{~A} \mathrm{a}$ \\
\hline 7 & $0.08 \pm 0.01 \mathrm{~A} \mathrm{a}$ & $0.10 \pm 0.02 \mathrm{~A} \mathrm{a}$ \\
\hline 14 & $0.08 \pm 0.01 \mathrm{~A} \mathrm{a}$ & $0.09 \pm 0.03 \mathrm{~A} \mathrm{a}$ \\
\hline 21 & $0.09 \pm 0.01 \mathrm{~A} \mathrm{a}$ & $0.10 \pm 0.06 \mathrm{~A} \mathrm{a}$ \\
\hline 60 & $0.09 \pm 0.01 \mathrm{~A} \mathrm{a}$ & $0.09 \pm 0.02 \mathrm{~A} \mathrm{a}$ \\
\hline \multirow[t]{2}{*}{100} & $0.07 \pm 0.00 \mathrm{~A} \mathrm{a}$ & $0.07 \pm 0.04 \mathrm{~A} \mathrm{a}$ \\
\hline & $\mathrm{L}$ & $\mathrm{L}$ \\
\hline 0 & $72.16 \pm 0.05 \mathrm{~B} \mathrm{~d}$ & $74.91 \pm 0.09 \mathrm{~A} \mathrm{~b}$ \\
\hline 7 & $72.49 \pm 0.22 \mathrm{~B} \mathrm{~cd}$ & $74.60 \pm 0.23 \mathrm{~A} \mathrm{~b}$ \\
\hline 14 & $72.52 \pm 0.05 \mathrm{~B} \mathrm{c}$ & $74.46 \pm 0.22 \mathrm{~A} \mathrm{~b}$ \\
\hline 21 & $72.87 \pm 0.10 \mathrm{~B} \mathrm{~b}$ & $74.57 \pm 0.21 \mathrm{~A} \mathrm{~b}$ \\
\hline 60 & $73.59 \pm 0.16 \mathrm{~B} \mathrm{a}$ & $75.86 \pm 0.24 \mathrm{~A} \mathrm{a}$ \\
\hline \multirow[t]{2}{*}{100} & $73.51 \pm 0.04 \mathrm{~B} \mathrm{a}$ & $76.24 \pm 0.68 \mathrm{~A} \mathrm{a}$ \\
\hline & $a^{*}$ & $a^{*}$ \\
\hline 0 & $-5.83 \pm 0.05 \mathrm{~B} \mathrm{~b}$ & $-2.10 \pm 0.02 \mathrm{~A} \mathrm{a}$ \\
\hline 7 & $-5.76 \pm 0.17 \mathrm{~B} \mathrm{~b}$ & $-2.59 \pm 0.32 \mathrm{~A} \mathrm{a}$ \\
\hline 14 & $-5.69 \pm 0.17 \mathrm{~B} \mathrm{~b}$ & $-2.69 \pm 0.29 \mathrm{~A} \mathrm{a}$ \\
\hline 21 & $-5.61 \pm 0.17 \mathrm{~B} \mathrm{ab}$ & $-2.82 \pm 0.27 \mathrm{~A} \mathrm{a}$ \\
\hline 60 & $-5.44 \pm 0.18 \mathrm{~A} \mathrm{ab}$ & $-5.14 \pm 0.49 \mathrm{~A} \mathrm{~b}$ \\
\hline \multirow[t]{2}{*}{100} & $-5.59 \pm 0.08 \mathrm{~A} \mathrm{a}$ & $-4.83 \pm 0.44 \mathrm{~A} \mathrm{~b}$ \\
\hline & $b^{*}$ & $b^{*}$ \\
\hline 0 & $44.87 \pm 0.11 \mathrm{~A} \mathrm{a}$ & $44.00 \pm 1.99 \mathrm{~A} \mathrm{ab}$ \\
\hline 7 & $44.74 \pm 0.25 \mathrm{~A} \mathrm{a}$ & $44.44 \pm 1.83 \mathrm{~A} \mathrm{ab}$ \\
\hline 14 & $44.26 \pm 0.45 \mathrm{~B} \mathrm{a}$ & $47.61 \pm 1.99 \mathrm{~A} \mathrm{a}$ \\
\hline 21 & $44.42 \pm 0.42 \mathrm{~A} \mathrm{a}$ & $46.84 \pm 2.17 \mathrm{~A} \mathrm{a}$ \\
\hline 60 & $43.95 \pm 0.36 \mathrm{~A} \mathrm{a}$ & $38.31 \pm 3.75 \mathrm{~A} \mathrm{~b}$ \\
\hline 100 & $41.83 \pm 0.41 \mathrm{~A} \mathrm{~b}$ & $26.37 \pm 4.05 \mathrm{~B} \mathrm{c}$ \\
\hline
\end{tabular}

Mean \pm standard deviation values followed by the same uppercase letter in line and by the same lowercase letter in column are not significantly different 
because the BNs were made with synthetic $\beta$-carotene, that is composed predominantly for trans- $\beta$-carotene. The absence of $\alpha$-carotene and cis-isomers of $\alpha$ - and $\beta$-carotene in the BNs made it more orange and red than the formulations of BALNs (Mortensen 2006).

The $b^{*}$ values in the BALNs and in the BNs were statistically lower, respectively, from the 100th and 60th day of storage. Thus, the formulation of the BNs became less yellow before that of the BALNs. And when the formulation factor was taken into account, it was possible to observe that the BNs presented lower $b *$ values than the BALNs from the 100th day of storage. Qian et al. (2013) commanded an experiment about the production of the lipid nanoparticles with the core composed of $\beta$-carotene by homogenizing cocoa butter and/or hydrogenated palm oil, the coordinates $a^{*}$ and $b^{*}$ presented a pronounced decrease during the 28 days of nanoparticles storage $\left(30^{\circ} \mathrm{C}\right)$.

\section{Particle Diameter and Zeta Potential}

Immediately after the preparation of the formulations (BALNs and $\mathrm{BNs})$, the volume-weighted mean diameter $\left(\mathrm{D}_{4,3}\right)$ by the LD of the samples was done. Through this parameter, it was possible to observe if there were a few micrometric contaminations, which should not be allowed in the formulations of the nanocapsules. The mean diameter $\left(D_{4,3}\right)$ of the BALNs was $142.33 \pm 5.69 \mathrm{~nm}$ with a span value of $1.24 \pm 0.03$, and the mean diameter $\left(\mathrm{D}_{4,3}\right)$ of the BNs was $190.33 \pm 32.81 \mathrm{~nm}$ with a span value of $1.71 \pm 0.13$ (Table 3 ). The span value in a suspension of nanocapsules is related to the homogeneity of the particles size distribution. Thus, the BALNs showed a higher homogeneity of the particles size distribution than the formulations of the BNs, due to possession of lower span values.

Similar values were found by Santos et al. (2015), that obtained lycopene entrapped in lipid-core nanocapsules with the PCL as wall material, the mean diameter $\left(\mathrm{D}_{4,3}\right)$ of these nanocapsules was $153 \mathrm{~nm}$ with a span value of 1.32. Contri et al. (2013) researched alternatives (Brazil nut, sunflower seed, olive, rose hip, grape seed, and carrot oils) to replace the oil core of the Eudragit RS100 ${ }^{\circledR}$ nanocapsules often made with capric/caprylic triglycerides and observed that the nanocapsules made with alternative oils presented a higher size $(280 \mathrm{~nm})$ and span value (2.50) than those made with capric/caprylic triglycerides. Thereby, the core composition of the particles influences the physico-chemical properties of these.

The DLS analysis demonstrated that formulations of BALNs and BNs presented monomodal size distributions in terms of intensity during the storage time (Fig. 3). This behavior was also shown with nanocapsules of indomethacin ester prepared by the same technique and amounts of materials in this study (Jäger et al. 2009). The data of the particle size distribution of this study corroborate those found by Ribeiro et al. (2008), where it was observed that both formulations, one stabilized with gelatin and the other with Tween ${ }^{\circledR} 20$, presented monomodal size distributions directly after preparation and over 5 months of cold storage $\left(4^{\circ} \mathrm{C}\right)$.

The zeta potential values indicate the level of stability of a colloidal system (Tiede et al. 2008). In module, the zeta potential values were significantly higher for the BALNs and lower for the BNs during all the days of storage. Benzophenone-3-loaded nanocapsules produced by the interfacial deposition of the preformed polymers method, have a similar zeta potential $(-9.5 \pm 1.0 \mathrm{mV})$ of the BNs (Paese et al. 2009). The difference between the zeta potential of the BALNs and the BNs is probably due to charge of different components of the formulations (Couvreur et al. 2002), since the BALNs that were produced with an ethanol extract from carrots should have, in addition to carotenoids ( $\beta$-carotene, $\alpha$ carotene, and lutein), other compounds.

Formulation and storage time factors provided no statistical difference between the values of the polydispersity index (PDI). The PDI is used to measure the degree of homogeneity of the sample (Hal et al. 1996). Considering the different formulations and storage time, the mean values of the PDI ranged from $0.07 \pm 0.04$ to $0.10 \pm 0.06$. It is known that PDI values from 0.1 to 0.25 indicate a fairly narrow size distribution while a PDI higher than 0.5 indicates a very broad distribution (Patravale et al. 2004). In this way, the formulations of this study were considered with a narrow size distribution, which improved the stability of formulations over the time.
Fig. 3 Size distribution (intensity), obtained by DLS, of BALNs (a) and BNs (b) formulations over the storage time $\left(4{ }^{\circ} \mathrm{C}\right)$
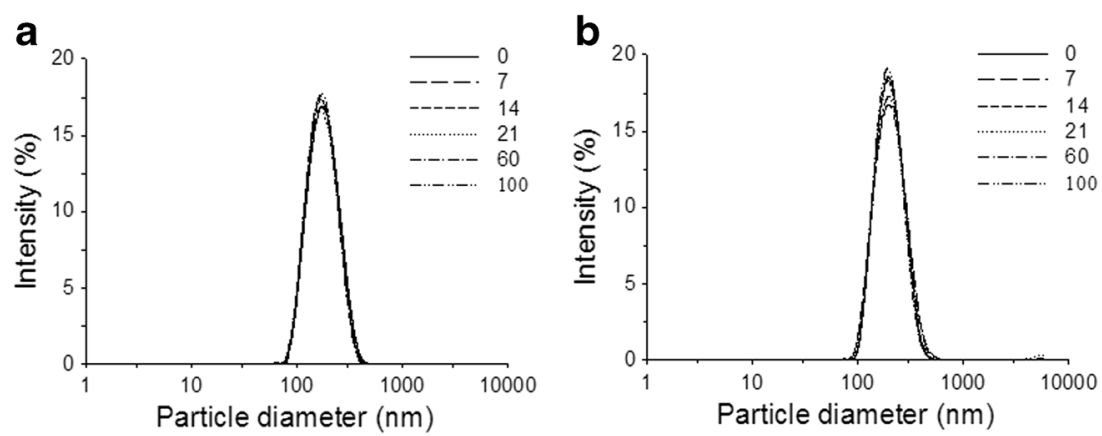


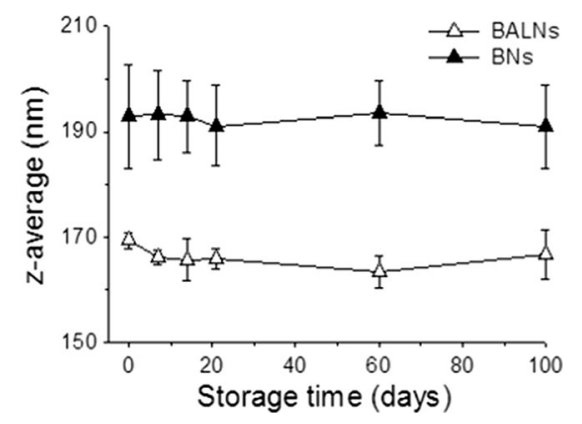

Fig. 4 Mean diameter ( $z$-average) of the BALNs and BNs formulations over the storage time $\left(4^{\circ} \mathrm{C}\right)$

The $z$-average of the formulations was also analyzed. The formulations of BALNs and BNs obtained a $z$-average lower than $200 \mathrm{~nm}$ (Fig. 4) immediately after the preparation, whereas in the same conditions of this work, Paese et al. (2009) produced benzophenone-3-loaded nanocapsules with a $z$-average of $247.00 \pm 4.00 \mathrm{~nm}$. The difference between the mean values of the $z$-average is related to the entrapped compound in the core of the particles, as well as the amount of this compound and the technique used.

The $z$-average was stable during the 100 days of storage, since there was no statistical difference between the days of storage (Fig. 4), it was from $169.27 \pm 1.50 \mathrm{~nm}$ to 166.53 $\pm 4.71 \mathrm{~nm}$ (BALNs) and from $192.97 \pm 9.77 \mathrm{~nm}$ to 190.90 $\pm 7.87 \mathrm{~nm}$ (BNs). In this study, it was observed that the BNs presented a higher $z$-average than the BALNs during all the days of storage, this was probably because of the ethanol extract used in the BALNs has other compounds in addition to the carotenoids. Bixin nanocapsules prepared by the interfacial deposition of the preformed polymers and stored at $25{ }^{\circ} \mathrm{C}$ also presented stable $z$-average values over the time (119 days). In a work done by Almeida et al. (2009) that aimed to produce and to characterize the oil-based nanoparticles containing alternative vegetable oils (grape seed oil and almond kernel oil), it was found that the $z$-average values of the formulations with grape seed oil showed similar mean diameter ( $z$-average) comparing the values obtained in the initial characterization and after 6 months of storage at room temperature. The stability of this type of nanocapsule formulation is attributed to the polymer wall that acts as an additional barrier to prevent coalescence and to the polysorbate 80 of which the mechanism of stabilization is the steric hindrance (Venturini et al. 2011).

\section{TEM}

The mean diameter of the BALNs and BNs done by the LD and DLS was confirmed by the TEM. It is noteworthy through the Fig. 5 that the two nanocapsule formulations showed a spherical shape and a mean diameter lower than $200 \mathrm{~nm}$. This spherical shape was also observed in nanocapsules produced by the same method used in the present study (Jäger et al. 2009). Pereira et al. (2015) used the same technique and the same conditions of morphological characterization of this work in a study with hydrophobic phytochemicals (Campomanesia xanthocarpa $\mathrm{O}$. Berg) nanoencapsulated with poly (DL-lactide-co-glycolide) through emulsionevaporation method. Even as in the present work, they observed that all particles presented a spherical shape and smooth surface, additionally, the particles showed diameters in the range of $200 \mathrm{~nm}$ in agreement with the result measured by the particle analyzer (Delsa TM Nano C Particle Analyzer, Beckman Coulter, Brea, CA, USA). Thus, it can be affirmed that the particle diameter carried by LD and DLS has a direct relationship with those carried out through TEM.

The data represented in Fig. 5 confirm those obtained by span values, since the span value of the BNs $(1.71 \pm 0.13)$ was greater than of the BALNs $(1.24 \pm 0.03)$. Then, the BNs formulation presented a lower homogeneity of particles size distribution than BALNs formulation.

\section{$\log D$}

The $\log \mathrm{D}$ was calculated in relation to the lipophilicity of the carotenoids. The $\log \mathrm{D}$ of the $\beta$-carotene and $\alpha$-carotene was 15.51 and 15.46 , respectively, and these values remained the
Fig. 5 TEM images of BALNs (a) and BNs (b) formulations immediately after the preparation (bar of $100 \mathrm{~nm}$ )
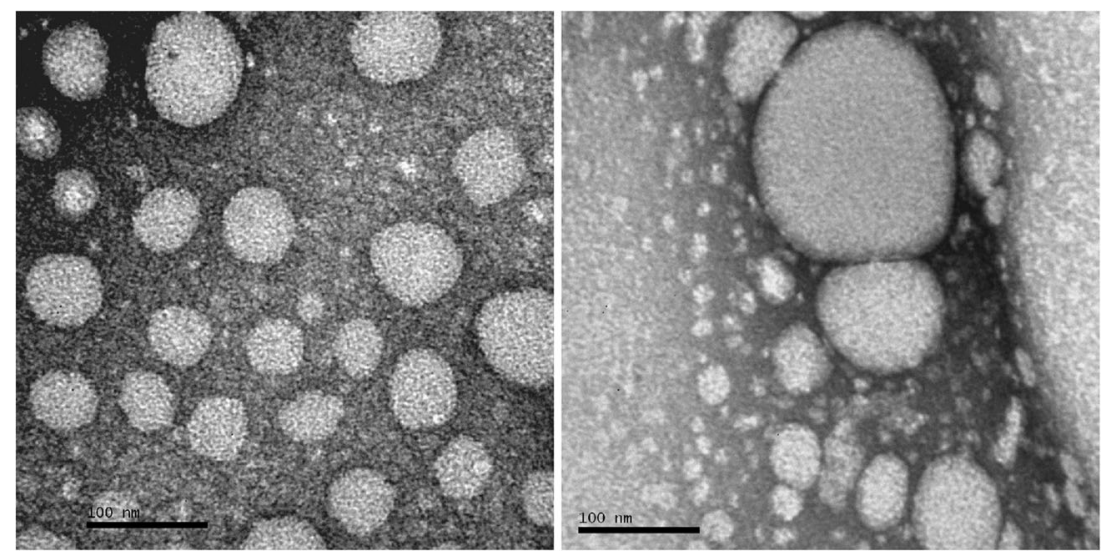
same in the $\mathrm{pH}$ range of $0-14$. And the $\log \mathrm{D}$ of the lutein was 11.78 in the $\mathrm{pH}$ range of $0-12.9$, this decreased to 11.67 at a $\mathrm{pH}$ of 14.00 . With these high values of $\log \mathrm{D}$, it is possible to assert that all carotenoids were located in the core of the nanocapsules, since, according to Oliveira et al. (2013), compounds with a $\log \mathrm{D}$ higher than 2.0 are poorly soluble in water. Hence, $\beta$-carotene, $\alpha$-carotene, and lutein are strongly linked to the core of the nanocapsules.

\section{Conclusions}

Carotenoids are beneficial compounds for health, characterized by low water-solubility, which hampers its use in foods rich in water. The nanoencapsulation technique emerges as an alternative to solve this obstacle. Through the results obtained in this study, success was observed in the production of the formulations of the BALNs and BNs by the interfacial deposition of the preformed polymer with $26 \mu \mathrm{g} / \mathrm{mL}$ of carotenoids content. Both formulations presented an encapsulation efficiency nearly of $100 \%$, a monomodal size distribution, a stable mean diameter $\left(\mathrm{D}_{4,3}\right.$ and $z$-average), and zeta potential during the 100 days of storage $\left(4^{\circ} \mathrm{C}\right)$. The $\mathrm{pH}$ and $\mathrm{b}^{*}$ coordinate values decreased with the storage time in the BALNs and BNs, and lower values of $b^{*}$ occurred due to loss of the carotenoids. The $z$-average of the BALNs and BNs at end of storage was, respectively, $166.53 \pm 4.71$ and $190.90 \pm 7.87$. This difference between the $z$-average of the formulations was probably due the composition of the ethanol extract used for the production of nanocapsules, since an ethanol extract from "Baltimore" carrots was used in the BALNs and an ethanol extract from synthetic $\beta$-carotene was used in the BNs. Despite the physical stability of the two formulations, the BALNs $(67.62 \pm 7.77 \%)$ retained more $\beta$-carotene content than the BNs $(11.69 \pm 1.65 \%)$ after 100 days of storage. This episode can be explained by the possible synergic effect that occurs among the compounds in the BALNs. This study highlights the production of nanocapsules composed by carotenoids obtained from a natural source (carrots), which can be in the future applied in food matrices rich in water, which will expand the use of the carotenoids, such as $\beta$-carotene, $\alpha$-carotene, and lutein, in different food products in an industrial scale.

Acknowledgments The authors are grateful to Coordenacão de Aperfeiçoamento de Pessoal de Nível Superior (CAPES, Brazil), Fundacão de Amparo à Pesquisa do Estado do Rio Grande do Sul (FAPERGS, Brazil), and Empresa Brasileira de Pesquisa Agropecuária (Embrapa, Brazil) for the financial support provided for this research and Eletronic Microscope Center (CME) of Federal University of Rio Grande do Sul UFRGS for technical assistance.

\section{References}

Almeida, J. S., Jezur, L., Fontana, M. C., Paese, K., Silva, C. B., Pohlmann, A. R., Guterres, S. S., \& Beck, R. C. R. (2009). Oilbased nanoparticles containing alternative vegetable oils (grape seed oil and almond kernel oil): preparation and characterization. Latin American Journal of Pharmacy, 28, 165-172.

Aparicio-Ruiz, R., Mínguez-Mosquera, M. I., \& Gandul-Rojas, B. (2011). Thermal degradation kinetics of lutein, $\beta$-carotene and $\beta$ cryptoxanthin in virgin olive oils. Journal of Food Composition and Analysis, 24, 811-820.

Bucić-Kojić, A., Planinić, M., Tomas, S., Jakobek, L., \& Šeruga, M. (2009). Influence of solvent and temperature on extraction of phenolic compounds from grape seed, antioxidant activity and colour of extract. International Journal of Food Science and Technology, 44, 2394-2401.

Can, E., Udenir, G., Kanneci, A. I., Kose, G., \& Bucak, S. (2011). Investigation of PLLA/PCL blends and paclitaxel release profiles. AAPS PharmSciTech, 12, 1442-1453.

Cao-Hoang, L., Fougère, R., \& Waché, Y. (2011). Increase in stability and change in supramolecular structure of $\beta$-carotene through encapsulation into polylactic acid nanoparticles. Food Chemistry, 124, 4249.

Contri, R. V., Ribeiro, K. L. F., Fiel, L. A., Pohlmann, A. R., \& Guterres, S. S. (2013). Vegetable oils as core of cationic polymeric nanocapsules: influence on the physicochemical properties. Journal of Experimental Nanoscience, 8, 913-924.

Couvreur, P., Barrat, G., Fattal, E., Legrand, P., \& Vauthier, C. (2002). Nanocapsule technology: a review. Critical Reviews in Therapeutic Drug Carrier Systems, 19, 99-134.

Das, S., \& Bera, D. (2013). Mathematical model study on solvent extraction of carotene from carrot. International Journal of Research in Engineering and Technology, 2, 343-349.

Fathi, M., Martín, A., \& Mcclements, D. J. (2014). Nanoencapsulation of food ingredients using carbohydrate based delivery systems. Trends in Food Science \& Technology, 39, 18-39.

Fiedor, J., \& Burda, K. (2014). Potential role of carotenoids as antioxidants in human health and disease. Nutrients, 6, 466-488.

Hal, D. A. V., Bouwstra, J. A., Rensen, A. V., Jeremiasse, E., Vringer, T., \& Junginger, H. E. (1996). Preparation and characterization of nonionic surfactant vesicles. Journal of Colloid and Interface Science, $178,263-273$.

Ilyasoglu, H., \& El, S. N. (2014). Nanoencapsulation of EPA/DHA with sodium caseinateegum arabic complex and its usage in the enrichment of fruit juice. Food Science and Technology, 56, 461-468.

Jäger, E., Venturini, C. G., Poletto, F. S., Colomé, L. M., Pohlmann, J. P. U., Bernardi, A., Battastini, A. M. O., Guterres, S. S., \& Pohlmann, A. R. (2009). Sustained release from lipid-core nanocapsules by varying the core viscosity and the particle surface area. Journal of Biomedical Nanotechnology, 5, 130-140.

Jin, H., Xia, F., Jiang, C., Zhao, Y., \& He, L. (2009). Nanoencapsulation of lutein with hydroxypropylmethyl cellulose phthalate by supercritical antisolvent. Chinese Journal of Chemical Engineering, 17, 672-677.

Liang, R., Shoemaker, C. F., Yang, X., Zhong, F., \& Huang, Q. (2013). Stability and bioaccessibility of $\beta$-Carotene in nanoemulsions stabilized by modified starches. Journal of Agricultural and Food Chemistry, 61, 1249-1257.

Liao, S., Chan, C. K., \& Ramakrishna, S. (2008). Stem cells and biomimetic materials strategies for tissue engineering. Materials Science and Engineering: C, 28, 1189-1202.

Linnewiel-Hermoni, K., Khanin, M., Danielenko, M., Zango, G., Amosi, Y., Levy, J., \& Sharoni, Y. (2015). The anti-cancer effects of carotenoids and other phytonutrients resides in their combined activity. Archives of Biochemistry and Biophysics, 572, 28-35. 
Lobato, K. B. S., Paese, K., Forgearini, J. C., Guterres, S. S., Jablonski, A., \& Rios, A. O. (2013). Characterisation and stability evaluation of bixin nanocapsules. Food Chemistry, 141, 3906-3912.

Mercadante, A. Z., \& Rodriguez-Amaya, D. B. (1998). Effects of ripening, cultivar differences, and processing on the carotenoid composition of mango. Journal of Agricultural and Food Chemistry, 46, $128-130$.

Mínguez-Mosquera, M. I., Hornero-Méndez, D., \& Pérez-Gálvez, A. (2007). Analysis of carotenoids and provitamin A in functional foods. In W. J. Hurst (Ed.), Methods of analysis in functional foods and added nutraceuticals (pp. 277-335). Boca Raton: CRC Press.

Mortensen, A. (2006). Carotenoids and other pigments as natural colorants. Pure and Applied Chemistry, 78, 1477-1491.

Mustafa, A., Trevino, L. M., \& Turner, C. (2012). Pressurized hot ethanol extraction of carotenoids from carrot by-products. Molecules, 17, 1809-1818.

Niizu, P. Y., \& Rodriguez-Amaya, D. B. (2005). New data on the carotenoid composition of raw salad vegetables. Journal of Food Composition and Analysis, 18, 739-749.

Oliveira, C. P., Venturini, C. G., Donida, B., Poletto, F. S., Guterres, I. S., \& Pohlmann, A. R. (2013). An algorithm to determine the mechanism of drug distribution in lipid-core nanocapsule formulations. Soft Matter, 9, 1141-1150.

Paese, K., Jäger, A., Pinto, E. F., Rossi-Bergmann, B., Pohlmann, A. R., \& Guterres, S. S. (2009). Semisolid formulation containing a nanoencapsulated sunscreen: effectiveness, in vitro photostability and immune response. Journal of Biomedical Nanotechnology, 5, $1-7$.

Patravale, V. B., Date, A. A., \& Kulkarni, R. M. (2004). Nanosuspensions: a promising drug delivery strategy. Journal of Pharmaceutics \& Pharmacology, 56, 827-840.

Pereira, M. C., Hill, L. E., Zambiazi, R. C., Talcott, S. M., Talcott, S., \& Gomes, C. L. (2015). Nanoencapsulation of hydrophobic phytochemicals using poly (DL-lactide-co-glycolide) (PLGA) for antioxidant and antimicrobial delivery applications: Guabiroba fruit (Campomanesia xanthocarpa O. Berg) study. LWT - Food Science and Technology, 63, 100-107.

Qian, C., Decker, E. A., Xiao, H., \& Mcclements, D. J. (2012). Physical and chemical stability of b-carotene-enriched nanoemulsions: influence of $\mathrm{pH}$, ionic strength, temperature, and emulsifier type. Food Chemistry, 132, 1221-1229.

Qian, C., Decker, E. A., Xiao, H., \& Mcclements, D. J. (2013). Impact of lipid nanoparticle physical state on particle aggregation and $\beta$ carotene degradation: potential limitations of solid lipid nanoparticles. Food Research International, 52, 342-349.

Rebecca, L. J., Sharmila, S., Das, M. P., \& Seshiah, C. (2014). Extraction and purification of carotenoids from vegetables. Journal of Chemical and Pharmacentical Research, 6, 594-598.

Ribeiro, H. S., Chu, B. S., Ichikawa, S., \& Nakajima, M. (2008). Preparation of nanodispersions containing b-carotene by solvent displacement method. Food Hydrocolloids, 22, 12-17.
Rodriguez-Amaya, D. B., Kimura, M., Godoy, H. T., \& Amaya-Farfan, J. (2008). Updated Brazilian database on food carotenoids: factors affecting carotenoid composition. Journal of Food Composition and Analysis, 21, 445-463.

Santos, P. P., Paese, K., Guterres, S. S., Pohlmann, A. R., Costa, T. H., Jablonski, A., Flôres, S. H., \& Rios, A. O. (2015). Development of lycopene-loaded lipid-core nanocapsules: physicochemical characterization and stability study. Journal of Nanoparticle Research, 17, $1-11$.

Silva, H. D., Cerqueira, M. A., Souza, B. W. S., Ribeiro, C., Avides, M. C., Quintas, M. A. C., Coimbra, J. S. R., Carneiro-da-Cunha, M. G., $\&$ Vicente, A. A. (2011). Nanoemulsions of $\beta$-carotene using a highenergy emulsification-evaporation technique. Journal of Food Engineering, 102, 130-135.

Stahl, W., \& Sies, H. (2003). Antioxidant activity of carotenoids. Molecular Aspects of Medicine, 24, 345-351.

Surles, R. L., Weng, N., Simon, P. W., \& Tanumihardjo, S. A. (2004). Carotenoid profiles and consumer sensory evaluation of specialty carrots (Daucus carota, L.) of various colors. Journal of Agricultural and Food Chemistry, 52, 3417-3421.

Tan, C. P., \& Nakajima, M. (2005). $\beta$-Carotene nanodispersions: preparation, characterization and stability evaluation. Food Chemistry, 92, 661-671.

Tiede, K., Boxall, A. B. A., Tear, S. P., Lew, J., David, H., \& Hasselöv, M. (2008). Detection and characterization of engineered nanoparticles in food and the environment. Food Additives \& Contaminants, 25, $795-821$.

U.S. Institute of Medicine. (2001). Dietary reference intakes for vitamin $A$, vitamin $K$, arsenic, boron, chromium, copper, iodine, iron, manganese, molybdenum, nickel, silicon, vanadium, and zinc. Washington, DC: National Academy Press.

Venturini, C. G., Jäger, E., Oliveira, C. P., Bernardi, A., Battastini, A. M. O., Guterres, S. S., \& Pohlmann, A. R. (2011). Formulation of lipid core nanocapsules. Colloids and Surfaces A: Physicochemical and Engineering Aspects, 375, 200-208.

Yi, J., Lam, T. I., Yokoyama, W., Cheng, L. W., \& Zhong, F. (2015). Betacarotene encapsulated in food protein nanoparticles reduces peroxyl radical oxidation in Caco-2 cells. Food Hydrocolloids, 43, 31-40.

Yin, L. J., Chu, B. S., Kobayashi, I., \& Nakajima, M. (2009). Performance of selected emulsifiers and their combinations in the preparation of $\beta$-carotene nanodispersions. Food Hydrocolloids, 23, $1617-1622$.

Zakaria-Rungkat, F., Djaelani, M., Setiana, M., Rumondang, E., \& Nurrochmah, E. (2000). Carotenoid bioavailability of vegetables and carbohydrate-containing foods measured by retinol accumulation in rat livers. Journal of Food Composition and Analysis, 13, 297-310.

Zimet, P., \& Livney, Y. D. (2009). Beta-lactoglobulin and its nanocomplexes with pectin as vehicles for $\mathrm{u}-3$ polyunsaturated fatty acids. Food Hydrocolloids, 23, 1120-1126. 